\title{
Perancangan Aplikasi Komputer Berbasis Android untuk Estimasi Biaya Reparasi Kapal Interaktif
}

\author{
Dave Hansel dan Triwilaswandio Wuruk Pribadi \\ Jurusan Teknik Perkapalan, Fakultas Teknologi Kelautan, Institut Teknologi Sepuluh Nopember (ITS) \\ Jl. Arief Rahman Hakim, Surabaya 60111 Indonesia \\ e-mail: triwilas.its@gmail.com
}

\begin{abstract}
Abstrak - Tujuan dari pengerjaan tugas akhir ini adalah untuk membuat suatu aplikasi komputer berbasis android yang berfungi sebagai media atau sarana dalam memperkirakan besarnya biaya reparasi kapal. Aplikasi ini berisikan item-item yang akan dikerjakan saat kapal akan melakukan docking. Item-item dan pekerjaan ini diambil berdasarkan repair list yang telah dibuat oleh galangan untuk pihak owner kapal. Tingginya permintaan reparasi kapal di galangan, membuat owner kapal harus menentukan anggaran biaya yang diperlukan ketika akan melakukan reparasi kapal pada saat kapal masih berada diatas laut. Software yang digunakan dalam pembuatan aplikasi ini adalah bahasa pemrograman PHP, Android Studio, dan MySQL. Aplikasi android interaktif ini mampu memberikan informasi berupa jenis-jenis pekerjaan reparasi yang dilakukan. Semua kebutuhan akan reparasi di input oleh owner kapal sendiri menyesuaikan dengan besar satuan yang akan dilakukan reparasi, kebutuhan material apa saja yang diperlukan $\&$ berapa jumlahnya. Setelah input yang diberikan telah selesai aplikasi ini akan memberikan besaran harga yang diperlukan, sehingga mampu memberikan kesempatan terhadap owner kapal dalam menyiapkan anggaran biaya untuk melakukan reparasi kapal. Setelah dilakukan analisa perbandingan sistem dan uji verifikasi dengan menguji aplikasi kepada pihak user, didapatkan bahwa aplikasi ini jauh lebih baik dibandingkan sistem eksisting yang dilakukan pemilik kapal untuk melakukan estimasi biaya, dengan nilai rata-rata hasil kuisioner 4,04 dengan nilai maksimum 5,00.
\end{abstract}

Kata Kunci-Aplikasi, Anggaran Biaya, Estimasi, Reparasi Kapal

\section{PENDAHULUAN}

$\mathrm{K}$ APAL sebagai transportasi laut akan mengalami kerusakan baik pada hull, konstruksi maupun peralatanperalatan yang ada pada kapal yang disebabkan oleh operasi kapal, dampak lingkungan maupun kecelakaan yang terjadi. Oleh karena itu untuk menstabilkan kondisi kapal agar dalam operasional kapal tetap optimal serta kondisi konstruksi maupun peralatan yang terdapat didalam kapal sebagai suatu sistem pendukung maupun inti tetap baik serta sesuai dengan persyaratan dan perbaikan secara rutin dan berkala. Pertumbuhan populasi kapal serta implementasi agenda pembangunan di bidang kemaritiman juga akan berdampak terhadap industri reparasi atau perbaikan kapal. Dengan demikian, industri perbaikan kapal juga ikut memiliki prospek yang cerah. Populasi galangan untuk kegiatan reparasi dengan kapasitas kecil ini mencapai 121 unit perusahaan atau 56,43\% dari total populsi galangan kapal untuk kegiatan reparasi yang mencapai 214 unit perusahaan [1]. Hal ini menyebabkan persaingan antara galangan kapal yang menyediakan fasilitas reparasi kapal untuk mengambil pangsa pasar tersebut dengan memperbaiki kualitas galangan yaitu kecepatan reparasi kapal, ketepatan waktu menyelesaikan pekerjaan reparasi, kualitas pekerjaan reparasi dan yang paling penting biaya reparasi yang murah. Dalam mengestimasi biaya reparasi kapal, pihak pemilik kapal biasanya menggunakan estimasi harga secara manual sehingga kadang kala pihak pemilik salah dalam menentukan harga reparasi kapal, hal ini dapat merugikan pihak pemilik karena anggaran atau dana yang disiapkan kurang dan tidak sesuai yang dianggarkan. Oleh karena itu seiring dengan kemajuan teknologi komunikasi diperlukan suatu aplikasi komputer berbasis android yang mampu menghitung secara cepat, tepat dan mendekati akurat dalam perhitungan estimasi biaya reparasi kapal yang dapat menyelesaikan permasalahan diatas. Sistem ini merupakan sistem yang dibuat oleh pihak galangan yang dapat diakses oleh pemilik kapal via smartphone yang terkoneksi dengan internet dan memiliki operating system $(O S)$ android sehingga di satu sisi, pihak galangan tidak rugi karena kesalahan dalam estimasi biaya dan pihak pemilik kapal dapat memperkirakan biaya reparasi kapalnya terlebih dahulu melalui aplikasi komputer berbasis android yang dapat diakses dari smartphone.

\section{URAIAN PENELITIAN}

\section{A. Estimasi Biaya}

Estimasi biaya adalah penghitungan kebutuhan biaya yang diperlukan untuk menyelesaikan suatu kegiatan atau pekerjaan sesuai dengan persyaratan atau kontrak. Dalam melakukan estimasi (perhitungan) biaya diperlukan pengetahuan dan keterampilan teknis estimator, seperti membaca gambar , melakukan estimasi, melakukan breakdown suatu pekerjaan, dll. Estimasi biaya yang bagus adalah rata rata statistik dari sejumlah perkiraan perkiraan untuk kebutuhan yang sama, yang menghasilkan nilai standar. Standar tersebut harus ditinjau secara berkala untuk mengukur validitas estimasi biaya yang dilakukan [2].

\section{B. Biaya Produksi Pada Galangan}

Produksi berlangsung dengan jalan mengolah masukan (input) menjadi keluaran (output). Masukan (input) merupakan pengorbanan biaya yang tidak dapat dihindarkan untuk 
melakukan kegiatan produksi. Setiap perusahaan harus dapat menghitung biaya produksi agar dapat menetapkan harga pokok barang yang dihasilkan. Untuk menghitung biaya produksi terlebih dahulu harus dipahami pengertiannya. Biaya produksi adalah sejumlah pengorbanan ekonomis yang harus dikorbankan untuk memproduksi suatu barang, menetapkan biaya produksi berdasarkan pengertian tersebut memerlukan kecermatan karena ada yang mudah diidentifikas, tetapi ada juga yang sulit diidentifikasi, biaya produksi dapat meliputi unsur - unsur sebagai berikut [3]:

1) Bahan baku atau bahan dasar termasuk bahan setengah jadi

2) Bahan - bahan pembantu atau penolong

3) Upah tenaga kerja dari tenaga kerja kuli hingga direktur

4) Penyusutan peralatan produksi

5) Uang modal dan sewa

6) Biaya penunjang seperti biaya angkut, biaya administrasi, pemeliharaan, biaya listrik, biaya keamanan, dan asuransi

7) Biaya pemasaran seperti biaya iklan

8) Pajak

Secara umum unsur biaya tersebut dapat dibagi atas tiga komponen biaya, berikut:

1) Komponen biaya bahan / material

2) Komponen biaya gaji / upah tenaga kerja

3) Komponen biaya umum (biaya over head pabrik) meliputi semua pengorbanan yang menunjang terselenggaranya proses produksi.

\section{Aktivitas Reparasi Kapal}

Aktifitas pekerjaan yang ada di galangan atau bidang usaha reparasi kapal secara umum terdiri dari aktifitas pengedokan, pembersihan kapal di bawah garis air, penggantian pelat, perbaikan sistem propulsi dan rudder, perbaikan machinery dan electrical. Dari keseluruhan aktifitas reparasi kapal yang dijabarkan secara umum beberapa diantaranya dari pekerjaan tersebut dikerjakan oleh bukan pekerja tetap atau biasa disebut dengan sub kontraktor [1]. Aktivitas tersebut secara garis besar dibagi menjadi:

1) Docking Undocking

2) General Services

3) Hull Working

4) Rantai, Jangkar, dan Bak Rantai

5) Cathodic Protection

6) Sea Chest and Valves

7) Plate Working

8) Pipe Working

9) Machinery and Other Equipment

10) Rudder and Population System

11) Electrical Working

\section{Aktivitas Reparasi Kapal}

Aplikasi Interaktif adalah penerapan dari rancang sistem untuk mengolah data yang menggunakan aturan atau ketentuan bahasa pemrograman tertentu dalam tugas akhir ini menggunakan Android, yang dibuat untuk mengerjakan dan melaksanakan tugas khusus dari pengguna (user) dengan saling aktif melakukan interaksi seperti pengguna (user) memberikan input data, aplikasi memberikan hasil (output) input dalam tugas akhir ini adalah besaran volume pekerjaan sedangkan output nya adalah estimasi biaya reparasi kapal [4].

\section{METODOLOGI PENELITIAN}

\section{A. Studi Literatur dan Studi Lapangan}

Studi literatur yang dilakukan untuk mengerjakan tugas akhir ini terdiri dari:

1) Analisis biaya pada reparasi kapal

2) Sistem estimasi biaya tradisional

3) Proses pekerjaan reparasi kapal secara umum

4) Jenis - jenis pekerjaan reparasi kapal

5) Pengantar sistem informasi

6) Sistem aplikasi komputer berbasis android

Sedangkan studi lapangan yang dilakukan dalam menyusun tugas akhir ini terdiri dari:

1) Pembiayaan reparasi kapal di lapangan

2) Proses pengerjaan reparasi di lapangan

3) Aktivitas dan penghitungan jam orang di lapangan

\section{B. Pengumpulan Data}

Tahapan ini adalah pengumpulan data yang menunjang dalam penulisan tugas akhir ini yang terdiri dari:

1) Proses bisnis umum dan alur proses bisnis reparasi kapal

2) Alur pembiayaan untuk reparasi kapal

3) Data aktifitas di galangan

4) Data biaya reparasi kapal

\section{Pembuatan Program Komputer Berbasis Android}

Adapun tahapan dalam membuat program ini antara lain:

1) Tahapan Awal

a. Diagram alur/ framework aplikasi

b. Diagram entity relationship

c. Desain file dan database pada server

d. Desain tampilan dan menu pada program Android Studio

e. Struktur tampilan dan keamanan

2) Tahapan Uji Coba

a. Tampilan program

b. Input data

c. Hasil output program

3) Tahapan Validasi

a. Uji validasi program dengan data perhitungan aktual di lapangan

b. Uji kepuasan dalam penggunaan program dengan kuisioner

c. Uji perbandingan perhitungan dengan sistem eksisting

\section{PERANCANGAN SISTEM APLIKASI}

Mengacu pada ide awal pembuatan aplikasi ini, terdapat suatu konsep yang dibuat untuk menentukan estimasi biaya reparasi kapal, sebelum dibuat dalam suatu program sebelumnya perlu diketahui bahwa alur program ini nantinya akan seperti pada Gambar 1. 


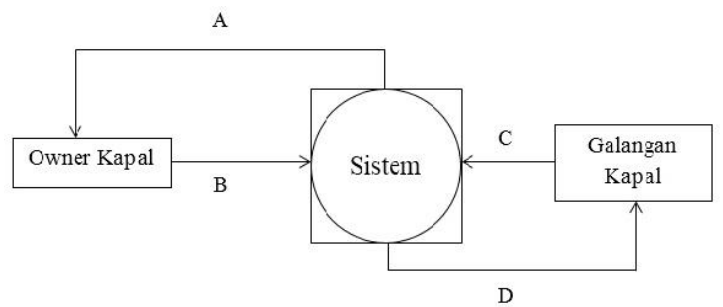

Gambar 1. Kerangka dasar perancangan sistem.

Keterangan:

A : Informasi harga reparasi kapal

B : Repair list, pekerjaan reparasi yang dilakukan, identitas kapal, dan jenis pekerjaan reparasi yang dibutuhkan

C : Informasi pengguna aplikasi (user), jenis pekerjaan yag dilakukan dan biaya nya

D : Update biaya reparasi kapal

Program yang akan dibuat sebagaimana mestinya untuk memudahkan penghitungan. Aplikasi ini dibangun untuk memudahkan pengguna, dimana kasus ini ditujukan kepada galangan maupun owner kapal yang akan melakukan reparasi kapal dan memerlukan perkiraan/ estimasi biaya yang dibutuhkan sehingga memudahkan untuk menyiapkan anggaran dana maupun kebutuhan material serta bagian bagian mana saja yang perlu diperbaiki. Program didesain dengan menggunakan beberapa penghitungan. Baik penghitungan biaya reparasi kapal dan penghitungan untuk pengingat/ reminder kapan dilakukannya survei/ docking selanjutnya [5]. Aplikasi ditujukan kepada seorang yang sudah memiliki background perkapalan/ orang galangan maupun owner kapal. Untuk alur sistem aplikasi secara keseluruhan dapat dilihat pada Gambar 2.

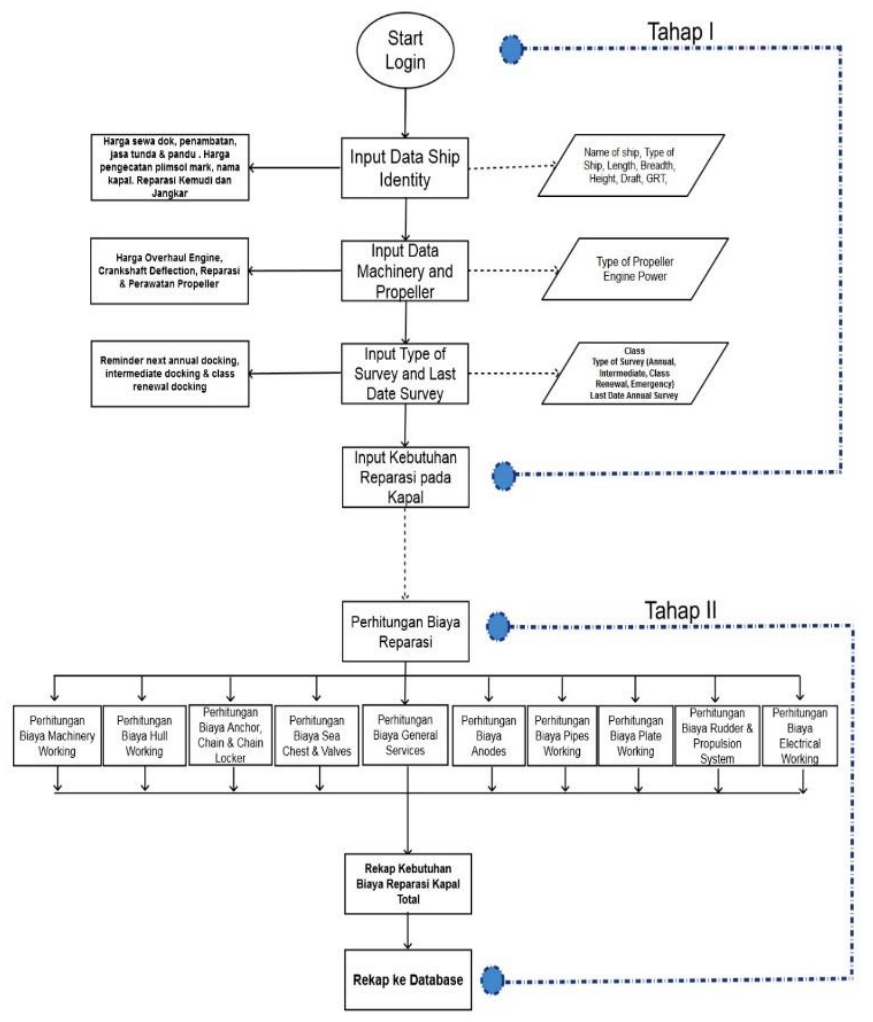

Gambar 2. Diagram alir penelitian
Pada gambar 2, alur aplikasi komputer terbagi menjadi 2 tahap, yaitu tahap I mulai dari login hingga input data identitas kapal dan tahap II dimana aplikasi komputer melakukan proses untuk menghitung estimasi biaya reparasi kapal. Setelah melakukan login maka secara otomatis pengguna aplikasi mengakses home interface seperti Gambar 3, melalui interface ini pengguna aplikasi dapat mengakses menu input atau mulai melakukan perhitungan di aplikasi.

\section{A. Menu Awal}

Dalam apliksi ini setiap penghitungan dibuat pada tab - tab yang menunjukan halaman proses penghitungan. Dibuat menjadi tab-tab terpisah untuk membuat interface lebih mudah. Pembagian tab-tab tersebut berdasarkan jenis-jenis pekerjaan reparasi kapal yang dilakukan di galangan. Proses input data atau volume pekerjaan dapat dimulai dari jenis pekerjaan paling atas yaitu hull working hingga electrical working atau random sesuai kebutuhan dari user sendiri.

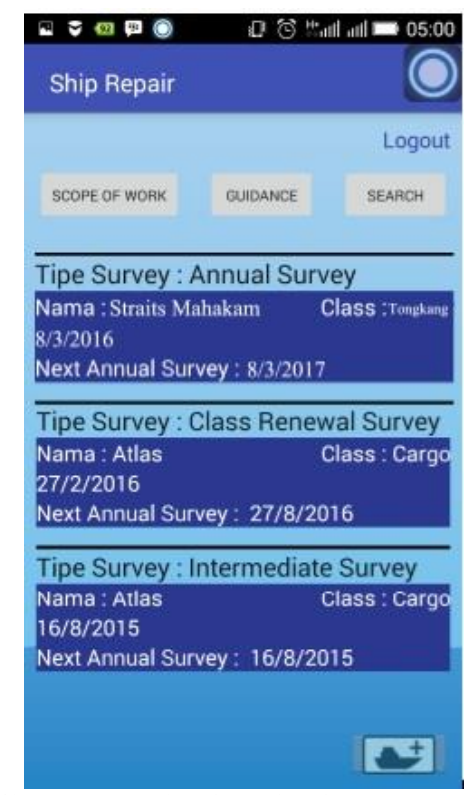

Gambar 3. Tampilan menu awal pada android system.

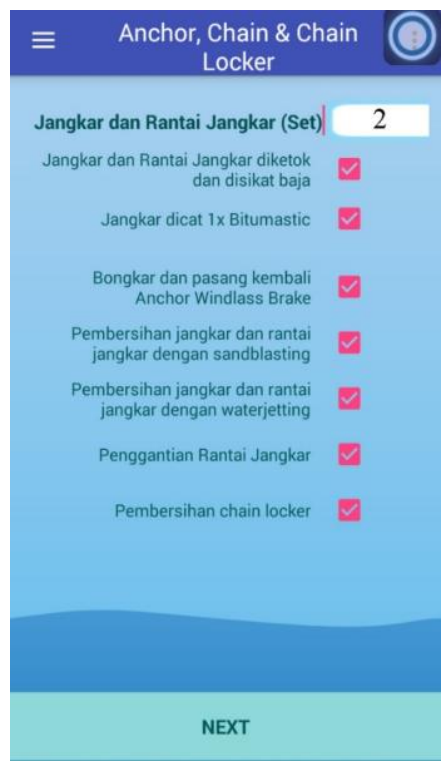

Gambar 4. Tab-tab jenis pekerjaan. 


\section{B. Input Pekerjaan Reparasi}

Proses penghitungan dapat dilakukan apabila seluruh isian atau input data yang ada sudah terisi seluruhnya. Seperti pada Gambar 4 berisi beberapa contoh inputan data reparasi kapal seperti berat penggantian baja, luasan pembersihan badan kapal, luasan pengecatan lambung kapal luar, jumlah zinc anode yang diganti, jumlah dan jenis valve yang diganti, dsb. Dengan inputan-inputan yang telah terisi lengkap dan jelas barulah proses perhitungan biaya dapat dilakukan, hal ini bertujuan untuk memberikan fokus kepada user dalam mengisi data tanpa harus memperhatikan harga terlebih dahulu, sehingga lebih terfokus pada inputan data.

\section{Sub Total Tiap Jenis Pekerjaan Reparasi}

Jika seluruh isian sudah selesai maka akan muncul rekap data biaya per pekerjaan, seperti rekap biaya pada Hull Working, Cathodic Protection, Plate Working, Electrical Working, dan lain-lain. Rekap biaya tersebut tidak hanya biaya total tetapi dilengkapi juga dengan breakdown dari biaya tersebut, yaitu Biaya Jasa dan Biaya Material seperti Gambar 5.

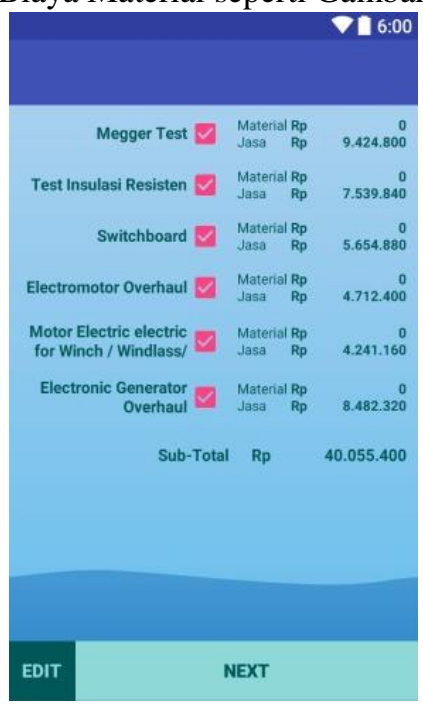

Gambar 5. Subtotal biaya tiap jenis pekerjaan.

\section{Rekap Biaya Total}

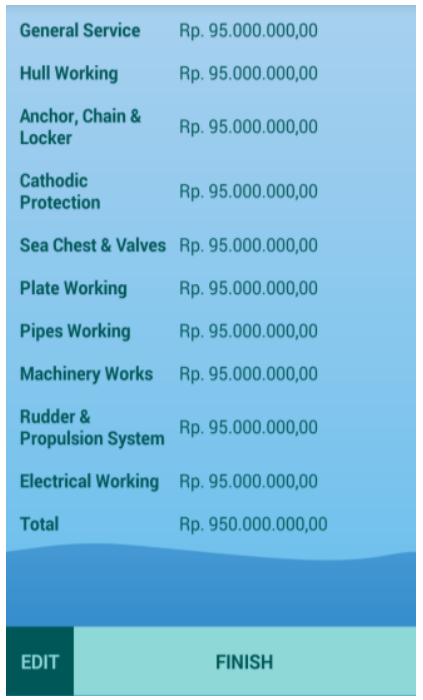

Gambar 6. Rekap Biaya Total.
Setelah menampilkan rekap biaya per item pekerjaan diatas, nanti akan terlihat juga rekap biaya keseluruhan dari reparasi kapal tersebut seperti pada Gambar 6, biaya tersebut merupakan biaya keseluruhan dari inputan data yang telah dilakukan sebelumnya. Setelah didapatkan rekap biaya keseluruhan , secara otomatis sistem akan menyimpan hasil input tadi kedalam database sehingga jika dilakukan pengisian kembali user dapat mudah untuk melakukan load data.

\section{KESIMPULAN}

Setelah melakukan penelitian dalam tugas akhir ini, maka dapat diambil kesimpulan sebagai berikut:

1) Sistem estimasi biaya reparasi kapal masih dilakukan secara manual memiliki kelebihan yaitu proses estimasi dilakukan oleh pihak estimator galangan yang melakukan perhitungan. Namun belum menggunakan suatu sistem atau aplikasi dan memiliki beberapa kelemahan diantaranya:

a. Proses waktu yang lama untuk menentukan biaya awal/ estimasi reparasi antar owner dan perusahaan galangan kapal.

b. Pemilik kapal/ owner tidak dapat memperkirakan/ mengestimasi besarnya estimasi biaya reparasi dengan cepat dan berdasarkan standart galangan.

c. Proses yang dilakukan begitu panjang dan lama alur untuk mengetahui berapa besar nya biaya reparasi kapal.

d. Belum ada fasilitas yang mengingatkan aktivitas sesuai biro klasifikasi (Annual Survey I, Annual survey II, Intermediate Survey, \& Class Renewal Survey).

2) Penentuan parameter-parameter dalam perhitungan biaya reparasi kapal dilakukan dengan cara studi literatur dan studi lapangan, dari hasil studi tersebut didapatkan parameter-parameter dalam penentuan biaya reparasi kapal diantaranya:

a. Informasi jenis perawatan dan perbaikan yang dilakukan di kapal

b. Volume dan quantity pekerjaan yang dilakukan

c. Fasilitas docking yang digunakan

d. Estimasi waktu lama kapal berada diatas dock

3) Berdasarkan hasil uji coba kepada pemilik kapal/ shipowner, aplikasi ini dapat berfungsi dengan baik dan cepat dalam memberikan informasi tentang estimasi biaya reparasi kapal. Dalam pengujian aplikasi ini menggunakan data kuisioner(responden) menunjukan bahwa aplikasi ini dapat bekerja dengan baik sesuai dengan nilai rata-rata pada hasil kuisioner yang telah dilakukan pengolahan data yaitu 4,04 dari nilai maksimum 5,00.

\section{UCAPAN TERIMA KASIH}

Penulis mengucapkan terima kasih kepada Ayah dan Ibu tercinta yang telah membesarkan penulis atas do'a, kasih sayang, dukungan, dan bimbingannya yang tidak pernah berhenti. Penulis mengucapkan terima kasih kepada Bapak Ir. Triwilaswandio Wuruk Pribadi, M.Sc dan Bapak Sufian Imam 
Wahidi, S.T, M.Sc. selaku dosen pembimbing yang telah membimbing penelitian ini sampai terbitnya jurnal ini.

\section{DAFTAR PUSTAKA}

[1] IPERINDO, "Laporan Direktori IPERINDO 2016," IPERINDO, Jakarta, 2016.

[2] M. S. Arief, Komputerisasi Estimasi Biaya Reparasi Kapal Berdasarkan Historical Data untuk Meningkatkan Efisiensi Activity Based Costing Berbasis Web, Surabaya: Jurusan Teknik Perkapalan-Intstitut Teknologi Sepuluh Nopember, 2012.

[3] B. D., A Guide to Ship Repair Estimates in Man-hours (Second Edition), Amsterdam: Elsevier Ltd., 2012.

[4] S. B., P. A. and U. C., Mudah dan Cepat Menguasai Aplikasi Komputer (Edisi Revisi), Bandung: INFORMATIKA, 2012.

[5] H. D., "Laporan Kerja Praktek: Bureu Veritas Indonesia," Fakultas Teknologi Kelautan ITS Surabaya, Surabaya, 2015. 